\title{
El sistema bibliotecario español
}

\author{
Luisa Orera Orera
}

Universidad de Zaragoza

Departamento de Ciencias de la Documentación

e Historia de la Ciencia

\subsection{Resumen}

Se describe la evolución del sistema bibliotecario en España desde su creación en el siglo XIX hasta nuestros días. Posteriormente centra su desarrollo en comentar el Sistema Bibliotecario Español, del cual tras enumerar sus bases legales, pasa a describir brevemente los diversos componentes que forman parte de él.

Palabras claves: Bibliotecas públicas. Sistemas bibliotecarios. Cooperación bibliotecaria.

\subsection{Abstract}

Description of the historical evolution of the library system in Spain from the 19 th century to the present. The current Spanish Library system is characterized, examining its legal basis and its different components.

Keywords: Public library. Library sistems. Interlibrary cooperation.

\section{Introducción}

En la actualidad, una nota inherente a la biblioteca es la cooperación. La cooperación en el mundo bibliotecario se impone tanto por razones de tipo económico, como por la misma concepción moderna de la biblioteca, que ha de caminar hacia un sistema de información cuya finalidad más importante es dar al usuario un servicio cada vez más perfecto, servicio que presenta dificultades para una biblioteca individual, que no puede ser autosuficiente. Es indudable en cambio, que la cooperación interbibliotecaria que permite al menos teóricamente disponer de fondos casi ilimitados, contribuye a perfeccionar este servicio.

Los sistemas bibliotecarios nacionales hay que situarlos en el marco de la cooperación interbibliotecaria, dentro de políticas de información tanto a nivel nacional como internacional. 
La ISO entiende por sistema bibliotecario: "Biblioteca o conjunto conectado de bibliotecas con todas sus divisiones, servicios y unidades que cooperan para servir a un área geográfica determinada en un campo temático concreto o un grupo específico de usuarios" (1). Según esta definición un sistema bibliotecario nacional es un conjunto conectado de bibliotecas con todas sus divisiones, servicios y unidades que cooperan para servir al territorio nacional. Para llevar a cabo esta cooperación el sistema bibliotecario necesita una infraestructura legislativa, material y personal que deben planificar los órganos competentes.

\section{Antecedentes Históricos (2)}

Para comprender la configuración del Sistema Bibliotecario Español en la actualidad, es preciso remontarse a sus orígenes, ya que dicho sistema se ha ido formando sobre una situación anterior que se ha transformado. Para el estudio de la evolución histórica del Sistema Bibliotecario Español podemos distinguir tres etapas:

$\left.1^{a}\right)$ Abarca todo el siglo XIX y el XX hasta 1931, en que se proclama la Segunda República.

$2^{\text {a) }}$ Ocupa el periodo comprendido entre 1931 y 1939, coincidente con la Segunda República.

$3^{\text {a) }}$ 1939-1975, época de la Dictadura Franquista.

A partir de 1975 entramos en la etapa actual del Sistema Bibliotecario Español (3).

Los antecedentes de la organización bibliotecaria actual hay que buscarlos en el siglo XIX. Es en este siglo cuando nace la biblioteca pública, base de dicha organización bibliotecaria.

Por otra parte, en el nacimiento de la biblioteca pública en España, pueden distinguirse dos grupos muy claros teniendo en cuenta su origen. El primero de estos grupos se origina en la denominada desamortización de Mendizábal. El segundo se configura para responder a la incipiente necesidad de lectura pública por parte de algunos sectores sociales, necesidad que fue recogida por algunas autoridades políticas.

Como hemos dicho anteriormente, un grupo de bibliotecas públicas españolas tiene su origen en la desamortización de Mendizábal (11-10-1835), mediante la cual se suprimen las comunidades religiosas (4).

En aquellas provincias donde no había otras bibliotecas o museos, los Institutos de Segunda Enseñanza de la capitales de provincia fueron los encargados de recoger los fondos bibliográficos procedentes de la desamortización. En ellos se formaron las primeras bibliotecas públicas. 
Saltan a la vista los problemas que, como bibliotecas públicas, presentaban aquellas bibliotecas:

- Por su ubicación, no cubrían las necesidades de la población rural.

- Las colecciones respondían a intereses de eruditos, clases cultas, etc, pero no a los intereses del ciudadano medio. Muchos de los libros llegados estaban en latín, griego, etc. Se daba el caso de la existencia en las colecciones de diccionarios griegos, árabes y hebreos en provincias donde no había nadie que conociera esta lenguas. Sus contenidos eran fundamentalmente religiosos. Los libros científicos más abundantes eran los de los siglos XVI, XVII y XVIII. Además no había obras literarias en castellano ni de información científica o histórica del momento. Por otra parte, los libros que ingresaron posteriormente no mejoraron la calidad de la oferta de lectura.

- Debido a la falta de personal cualificado, los fondos no recibían el tratamiento técnico adecuado. Este problema llevó en 1856 a la creación de la Escuela de Diplomática para expedir el título de Paleógrafo, que más tarde se convirtió en el de archivero bibliotecario. Posteriormente, por el Decreto de 17 de julio de 1858 (Ministerio de Fomento), se crea el Cuerpo Facultativo de Archiveros-Bibliotecarios (G. 18-7-1858).

- A través de todo lo anteriormente dicho, se pone de manifiesto que las bibliotecas públicas de España nacen con el lastre de ser entidades conservadoras del fondo desamortizado. En realidad más que bibliotecas públicas son un sistema de recogida y conservación del patrimonio bibliográfico. Pero a pesar de estos problemas, la creación de estas bibliotecas supone el nacimiento de una incipiente organización bibliotecaria a nivel nacional:

- Se crea una red que aprovecha bibliotecas y archivos existentes como las de las universidades y las de los institutos de enseñanza secundaria.

- Hemos visto también que en cuanto a personal va a existir un proyecto general, con la creación del Cuerpo Facultativo de ArchiverosBibliotecarios, que son técnicos empleados y pagados por el Estado, que atienden fondos de titularidad estatal.

- El "sistema" de bibliotecas cubre necesariamente todo el territorio nacional, puesto que se define de antemano cual es la biblioteca a la cual van a ir a parar los fondos desamortizados.

En cuanto al segundo grupo de bibliotecas al que nos hemos referido, presentan características diferentes.

La célebre Ley de Instrucción Pública (1857), conocida como "Ley Moyano", porque fue el Ministro de Fomento Claudio Moyano quien la propuso, se ocupa de las bibliotecas y más concretamente en el artículo 163 donde dice: 
"Que el Gobierno promoverá los aumentos y mejoras de las bibliotecas existentes; cuidará de que en ninguna provincia deje de haber a lo menos, una biblioteca pública y dictará las disposiciones convenientes para que en cada una haya aquellas obras cuya lectura pueda ser más útil, atendidas las circunstancias especiales de la localidad y del establecimiento a que pertenezca". Esta disposición demuestra ya una preocupación por modernizar las bibliotecas. Las bibliotecas públicas no debían servir sólo para recoger los viejos libros de los conventos, sino para satisfacer los gustos, aficiones, etc. de los lectores.

Las ideas de la Revolución de Septiembre de 1868 -La Gloriosa- influyeron en el campo de la lectura popular, que tenía otras necesidades que la lectura superior. En 1869, por Real Decreto de 18 de enero, se crean las bibliotecas populares. Eran bibliotecas cuyas colecciones deberían estar formadas por obras referidas a materia propias de la primera enseñanza y a conocimientos útiles, prácticos y elementales de ciencias, artes, arquitectura e industria, dirigidos a completar la enseñanza primaria. El sostenimiento y conservación de las bibliotecas correspondía a las diputaciones y ayuntamientos. Se ubicaban en las escuelas y el maestro era el responsable.

En cuanto a organización bibliotecaria se refiere, hay que decir que en 1869 se crea una pequeña unidad administrativa, que se denominó Negociado de Bibliotecas Populares que se ocupaba exclusivamente de este tipo de bibliotecas. Posteriormente pasó a ser una Sección (5).

En cuanto desaparecieron los efectos de la Revolución, estas realizaciones cayeron en el olvido (6). De todas formas, frente a la corriente conservadora, y esta vez en el sentido literal de la palabra, se fue abriendo paso una corriente popular que consideraba que los libros proporcionados por las bibliotecas públicas no debían ser sólo para una minoría culturalmente superior. Había numerosas personas con estudios elementales y medios, que tenían derecho a que se formaran bibliotecas para ellos o a que se reorientaran las ya existentes.

Durante la segunda etapa que hemos distinguido en este estudio histórico, y que coincide con la Segunda República, la organización bibliotecaria española experimentará un fuerte impulso.

Las bibliotecas populares se desarrollaron mediante el llamado Patronato de Misiones Pedagógicas, que se proponía difundir la cultura en general, llevar a acabo una moderna orientación docente y hacer llegar la educación ciudadana al medio rural. En esta labor, a las bibliotecas populares se les iba a dar un importante papel, por lo que el Patronato dedicó al desarrollo de las mismas el 60\% de su presupuesto, consiguiendo crear antes del comienzo de la guerra más de 5.000 pequeñas bibliotecas de 100 volúmenes cada una, dedicados a niños y adultos. 
Estas colecciones se ubicaba preferentemente en las escuelas de los medios rurales (7).

La Segunda República, aparte de impulsar la creación de bibliotecas, se ocupó de la organización bibliotecaria. Existen una serie de hechos que lo ponen de manifiesto:

1) En 1931 se crea la Junta de Intercambio y Adquisición de Libros para las bibliotecas públicas, dicha Junta será un órgano encargado de la política bibliotecaria específica de las bibliotecas públicas.

2) Durante el periodo republicano se elabora también un plan para bibliotecas públicas, propuesto por María Moliner. En él las bibliotecas públicas del Estado se dividen en generales, escolares, históricas, científicas y administrativas. En dicho Plan está prevista la creación de una serie de órganos centrales para coordinar el funcionamiento del sistema bibliotecario estatal:

a) La Sección de Bibliotecas, órgano ministerial encargado de la política bibliotecaria.

b) Una Oficina de adquisición de libros encargada tanto de dicha adquisición como de su distribución a toda la red de bibliotecas públicas, conocidas en el Plan como bibliotecas generales.

c) Un Equipo de catalogadores para tratar los libros adquiridos por la oficina y también para desplazarse en determinadas ocasiones a las bibliotecas incorporadas a la red para prestar ayuda técnica.

d) Un Depósito de libros para albergar tanto los pendientes de distribución a las diferentes bibliotecas, como los expurgados.

e) Una Oficina del Catálogo General, encargada de gestionar el catálogo colectivo de las bibliotecas pertenecientes a la red.

f) Una Oficina de Información Bibliográfica.

g) Una Escuela Nacional de Bibliotecarios, y en relación con ella, una Oficina de Información Biblioteconómica.

h) Una Oficina de Inspección y Propaganda, que se encargaría de inspeccionar, de dar normas, así como organizar campañas para la difusión de la lectura.

i) El Cuerpo General de Bibliotecarios.

j) Un Servicio Central de Desinfección, encargado de planificar, controlar y llevar a cabo las medidas necesarias para la conservación del libro. 
Además de todo ello, a la Biblioteca Nacional se le daba el papel de cabecera del Sistema Bibliotecario.

En cuanto a la distribución geográfica de las bibliotecas, el Plan preveía una serie de escalones o servicios:

- Las bibliotecas provinciales

- Las bibliotecas comarcales

- Los depósitos, en lugares de 500 habitantes, para los cuales se planificaba que no hubiera un fondo permanente, sino lotes renovables

- Los corresponsales, existentes en pequeñas aldeas en las cuales no había depósitos de libros. En ellas el corresponsal, que disponía de los catálogos de las bibliotecas más próximas y de la provincial, se encargaba de tramitar las peticiones de préstamo de los ciudadanos.

A través de todo lo dicho puede afirmarse que: "En el Plan de María Moliner hay ya un sistema nacional de bibliotecas que tiene además como esqueleto básico las bibliotecas públicas" (8). Sin embargo, el Plan no llegó a aplicarse por la desaparición de la República.

La tercera etapa de este recorrido histórico abarca, como hemos indicado, desde el final de la Guerra Civil hasta 1975. Durante la misma, se llevaron a cabo una serie de realizaciones dirigidas a configurar el Sistema Bibliotecario Español. En primer lugar, hay que hacer constar que la Junta de Intercambio y Adquisición de Libros se sustituye por la Dirección General de Archivos y Bibliotecas, creada por Ley de 25 de agosto de 1939. Por otra parte, la organización bibliotecaria en lo que a aspectos legislativos se refiere, queda regulada por el Decreto de 24 de julio de 1947, del Ministerio de Educación Nacional, por el que se dan normas para la ordenación de Archivos y Bibliotecas (BOE 17 de agosto de 1947).

El sistema bibliotecario en esta etapa queda definido sobre todo por:

1) El Servicio Nacional de Lectura. Creado por el Decreto de 24 de julio de 1947, del Ministerio de Educación Nacional, por el que se dan normas para la ordenación de Archivos y Bibliotecas (BOE 17 de agosto de 1947), sus funciones se desarrollan por el Reglamento de 4 de julio de 1952, en el que se establecen como más importantes, las siguientes:

a) Hacer llegar el libro a todo el territorio nacional

b) Comprar los libros necesarios para todas las bibliotecas públicas. Para ello se encargaba de la tramitación de las peticiones de compra y de las facturas correspondientes, presentadas y conformadas por las bibliotecas públicas provinciales y los centros coordinadores. 
c) Promover la creación de nuevos centros coordinadores y de nuevas bibliotecas públicas municipales.

d) Dotar a las bibliotecas públicas municipales de un fondo bibliográfico inicial.

e) Organizar la Biblioteca Central Circulante para el préstamo interbibliotecario nacional.

2) Las bibliotecas públicas provinciales. Dependían del Servicio Nacional de Lectura.

3) Los centros provinciales coordinadores de bibliotecas. Tienen su origen en una Orden de 18 de noviembre de 1940, por la que se concede carácter oficial al Centro Coordinador de Bibliotecas creado por la Diputación de Oviedo.

Tomando como modelo Asturias, se decide crear un centro coordinador por provincia que se ocupará, como órgano delegado del poder central, del desarrollo bibliotecario en la demarcación.

Los centros provinciales coordinadores de bibliotecas tenían como misión:

- Elaborar los planes bibliotecarios provinciales

- Inspeccionar y proporcionar ayuda técnica a las bibliotecas públicas de la provincia.

- Promocionar la creación de bibliotecas públicas municipales en la provincia.

- Encargarse de organizar una biblioteca circulante para el préstamo interbibliotecario de la provincia.

Dichos centros, funcionaban mediante la colaboración presupuestaria de: el Ministerio, a través del servicio Nacional de Lectura, que subvencionaba la compra de libros; las diputaciones provinciales, que se hacían cargo de los gastos generales y los ayuntamientos, que se ocupaban de proporcionar o pagar locales para instalar las bibliotecas, así como de pagar al personal.

A través de todo ello, se creó una organización bibliotecaria nacional, basada en la existencia de sistemas bibliotecarios provinciales cuya conexión se llevaba a cabo unificando la dirección técnica del centro coordinador y de la biblioteca pública del estado correspondiente, que recaía en un único funcionario del Cuerpo Facultativo de Archivos y Bibliotecas (9).

\section{El Sistema Bibliotecario Español en la actualidad}

A partir de 1975 el Sistema Bibliotecario Español va a verse afectado por una serie de cambios, la mayoría de los cuales tienen su origen en la nueva organiza- 
ción del Estado: se pasa de un Estado centralista a un Estado de las autonomías. La aparición de las nuevas administraciones autonómicas requieren la adaptación del Sistema a la nueva situación. Este y otros factores determinarán la configuración actual del Sistema Bibliotecario Español del que nos vamos a ocupar en este apartado y sobre el que hay que señalar que en este momento sólo está desarrollado en lo que a bibliotecas públicas se refiere.

\subsection{Bases Legales del Sistema Bibliotecario Español}

En primer lugar es necesario referirse a las disposiciones legales en las que se apoya, ya que aunque es obvio que un sistema bibliotecario no se agota en el marco legislativo, es evidente que constituye el paso previo necesario para que dicho Sistema exista. Por otra parte, este trabajo no se propone agotar todos los aspectos relacionados con el Sistema Bibliotecario Español. Por esta razón vamos a detenernos en primer lugar en el análisis, somero, de aquellas normas legislativas que contribuyen a delimitarlo:

\subsubsection{Constitución Española.}

La Constitución española divide las bibliotecas públicas en dos grupos:

- De titularidad no estatal, sobre las cuales tienen competencia exclusiva las comunidades autónomas: "Las Comunidades Autónomas podrán asumir competencias en... bibliotecas... de interés para la Comunidad Autónoma" (10)

- De titularidad estatal, con la posibilidad de gestión por parte de las comunidades autónomas: "El Estado tiene competencia exclusiva sobre... bibliotecas... de titularidad estatal, sin perjuicio de su gestión por parte de las Comunidades Autónomas" (11)

La Constitución establece también: "Sin perjuicio de las competencias que podrán asumir las Comunidades Autónomas, el Estado considerará el servicio de la cultura como deber y atribución esencial y facilitará la comunicación cultural entre las Comunidades Autónomas, de acuerdo con ellas" (12)

\subsubsection{Estatutos de Autonomía}

Los estatutos de autonomía son leyes orgánicas en las cuales se recogen las competencias atribuidas por la Constitución Española a las distintas comunidades autónomas, en distintas materias y entre ellas las bibliotecas.

\subsubsection{Decretos de Transferencia.}

Una vez que la Constitución y los estatutos de autonomía delimitan las competencias del Estado y de las comunidades autónomas, aquellas competencias que antes ejercía el Estado y que han sido cedidas a las distintas comunidades autónomas han de ser transferidas. Ello se lleva a cabo a través de los decretos de 
transferencias.

3.1.4. Normativa del Estado de aplicación general sobre bibliotecas

- Ley 16/1985, de 25 de junio, del Patrimonio Histórico Español (BOE nº. 155, de 29 de junio de 1985).

- Real Decreto 111/1986, de 10 de enero, de desarrollo parcial de la Ley 16/1985 (BOE nº. 24, de 18 de enero de 1986).

- Ley 7/1985, de 2 de abril, Reguladora de las Bases del Régimen Local (BOE $n^{\circ} .80$, de 3 de abril de 1985), que establece en su artículo 26 que: "En los municipios con población superior a 5.000 habitantes, éstos deberán prestar como servicio básico el de la biblioteca pública".

- Real Decreto 565/1985, de 24 de abril, que reestructura la organización y funciones del Ministerio de Cultura, Ministerio encargado de todos los temas concernientes a la lectura y a las bibliotecas a través de su Dirección General del Libros y Bibliotecas. Posteriormente, se han sucedido distintos reales decretos que han puesto al día el organigrama de dicho Ministerio. El último (13), crea el Ministerio de Educación y Cultura, atribuyéndole las competencias que hasta entonces correspondían a ambos ministerios.

\subsubsection{Normativa del Estado sobre bibliotecas públicas}

Por el Real Decreto 582/1989, de 19 de mayo, (BOE n ${ }^{\circ}$ 129, de 31 de mayo de 1989), se aprueba el Reglamento de Bibliotecas del Estado y del Sistema Español de Bibliotecas.

Fundamentado en la Ley 16/1985, del Patrimonio Histórico Español, el Reglamento se divide en dos títulos diferenciados: el primero de ellos se refiere a las Bibliotecas Públicas del Estado definiendo su naturaleza, funciones, organización, condiciones de acceso y servicios. El segundo, trata del Sistema Español de Bibliotecas al que define como instrumento de cooperación bibliotecaria, señalando las bibliotecas de titularidad pública que forman parte del Sistema así como la posibilidad de integrarse en el mismo mediante convenio por parte de otras bibliotecas, sean de carácter tanto público como privado.

A partir de dicho Reglamento se crea el Consejo Coordinador de Bibliotecas, dependiente del Ministerio de Cultura, cuyo objetivo prioritario es la modernización de las bibliotecas públicas, entendiendo dentro de esta modernización la racionalización de la gestión bibliotecaria y la optimización de todos los recursos bibliográficos y documentales. 
3.1.6. Normas de las distintas comunidades autónomas en materia de biblioteca (14)

Son las distintas disposiciones legales específicas de bibliotecas, emanadas de las distintas comunidades autónomas y que fundamentan sus sistemas bibliotecarios.

\subsubsection{Convenios de Gestión entre el Estado y las comunidades autónomas}

Mediante los convenios de gestión firmados entre el Ministerio de Cultura y las distintas comunidades autónomas, las bibliotecas públicas de titularidad estatal pasan a ser gestionadas por las correspondientes Autonomías.

\subsection{Descripción del Sistema Bibliotecario Español}

El Real Decreto 582/1989, de 19 de mayo, en su Título II determina que el Sistema Español de Bibliotecas está integrado por:

- La Biblioteca Nacional, que se configura como cabecera del sistema.

- Las Bibliotecas Públicas del Estado.

- Las bibliotecas dependientes de los ministerios y Organismos Autónomos de la Administración del Estado, excluidas las escolares.

- Las Bibliotecas de las Universidades públicas.

- Las Bibliotecas de las Reales Academias.

- Las redes o sistemas de bibliotecas de Instituciones públicas o privadas o las bibliotecas de excepcional interés que se incorporen, mediante convenio con el Ministerio de Cultura.

El actual sistema bibliotecario, como ya hemos señalado antes, queda condicionado por el nacimiento de las comunidades autónomas como poder político, que junto con la administración local y el Estado, van a repartirse las competencias en bibliotecas públicas. Por ello, en el Sistema Bibliotecario Español, podemos distinguir dos ámbitos: el estatal y el autonómico. El primero se sustenta en la Dirección General del Libro, Archivos y Bibliotecas, enmarcada dentro del Ministerio de Educación y Cultura; en la Biblioteca Nacional y en la Red de bibliotecas públicas de titularidad estatal. El segundo, apoyándose en las competencias exclusivas ejercidas por las comunidades autónomas en las bibliotecas públicas que no son de titularidad estatal; la gestión de las de titularidad estatal y las competencias de la administración local en bibliotecas públicas, ha configurado los sistemas bibliotecarios autonómicos.

\subsubsection{La Dirección General del Libro, Archivos y Bibliotecas}

El Real Decreto 1887/1996, de 2 de agosto, le atribuye las siguientes funciones en el campo de las bibliotecas públicas: 
“a) La elaboración de programas y planes concertados para la constitución y fomento de bibliotecas, mediante la oferta de servicios técnicos y asesoramiento en materia bibliotecaria.

La creación, dotación y fomento del bibliotecas de titularidad estatal, sin perjuicio de la gestión de las mismas convenida o que pudiera convenirse con las comunidades autónomas.

El diseño y desarrollo de campañas de utilización de bibliotecas.

La obtención, explotación y utilización de datos estadísticos de bibliotecas.

La asistencia bibliotecaria a sectores especiales de población que no pueden utilizar los servicios habituales de las bibliotecas públicas" (15).

El mismo Real Decreto atribuye la ejecución de estas funciones a la Subdirección General de Coordinación Bibliotecaria, dependiente de la Dirección general del Libro, Archivos y Bibliotecas.

El Ministerio de Educación y Cultura dispone del Consejo Coordinador de Bibliotecas como órgano consultivo, creado por el artículo 24 del Título II del Real Decreto 582/1989, de 19 de mayo, que le atribuye las siguientes funciones:

- Informar sobre las normas técnicas relativas a bibliotecas.

- Informar, igualmente, los programas de cooperación interbibliotecaria.

- Promover la formación de los Catálogos Colectivos y la interconexión de los servicios automatizados de las bibliotecas del Sistema.

- Proponer cuantas otras medidas estime oportuno para el desarrollo de la cooperación bibliotecaria y la implantación del Sistema Español de Bibliotecas.

A la vista de todo ello, el Consejo podría ejercer un importante papel en la implantación del Sistema, ya que está integrado por representantes de todo tipo de bibliotecas: universitarias, de CSIC, de los ministerios, etc.

\subsubsection{La Biblioteca Nacional}

El papel de la Biblioteca Nacional como cabecera del Sistema Bibliotecario Español, aparece claramente expresado en el Real Decreto 582/1989, de 19 de mayo. Esta y otras misiones que como biblioteca nacional tiene encomendadas tanto en el plano nacional como internacional, a la vez que los grandes problemas con los que se enfrentan en la actualidad todas las bibliotecas nacionales, han llevado a la Biblioteca Nacional a profundas reformas tanto en el marco físico como en su estructura organizativa.

La estructura actual de la Biblioteca Nacional (16) comienza a gestarse en 1985, buscando un modelo que permitiera hacer frente a los grandes retos con que se enfrenta la Biblioteca Nacional. El Real Decreto 565/1985, de 24 de abril, por el que se establece la estructura orgánica básica del Ministerio de Cultura y

Scire. 2 : 2 (jul.-dic. 1996) 99-120 
de sus organismos autónomos (BOE de 30 de abril de 1985), determinaba en el artículo 6.6 la integración dentro de la Biblioteca Nacional de:

- La Hemeroteca Nacional

- El Instituto Bibliográfico Hispánico.

- El Centro del Tesoro Documental y Bibliográfico.

Como organismo independiente se establecía en el Real Decreto anteriormente citado, la Biblioteca Nacional de Préstamo, que sólo fue un proyecto derogado por el Real Decreto 834/1989, de 7 de julio, por el que se modifica la estructura orgánica básica del Ministerio de Cultura y sus organismos autónomos (BOE del 12 de julio), cuya Disposición Adicional Primera 3, suprime la Biblioteca Nacional de Préstamo incorporando este servicio a la Biblioteca Nacional.

El Real Decreto 848/1986, de 25 de abril (BOE de 30 de abril de 1986), determinó las funciones y la estructura orgánica básica de la Biblioteca Nacional. Dicha estructura básica se desarrollaría posteriormente por Orden del Ministerio de Cultura de 10 de junio de 1986 (BOE del 21 de junio).

La Biblioteca Nacional a partir de 1990 (17) se constituye en organismo autónomo de carácter administrativo, adscrito al Ministerio de Cultura, condición que se ratifica en el Real Decreto 1581/1991, de 31 de octubre, por el que se aprueba el Estatuto de la Biblioteca Nacional (BOE de 8 de noviembre de 1991), modificado por el real Decreto 253/1997, de 21 de febrero (BOE ${ }^{\circ} 54$, de 4 de marzo de 1997).

Desde 1993 (18) la Biblioteca Nacional, enmarcada dentro de la estructura orgánica del Ministerio de Cultura, depende directamente del Ministro. Dicha dependencia queda confirmada por el Real Decreto 2045/1994, de 14 de octubre, por el que se establece la estructura básica del Ministerio de Cultura (BOE de 20 de octubre) (19).

Dentro de todas las funciones encomendadas a la Biblioteca Nacional por la legislación vigente, interesa aquí la de ser cabecera del Sistema Bibliotecario Español, función que ha de llevar a cabo a través de distintos medios. De éstos destacamos:

- La colección nacional, basada fundamentalmente en los ingresos procedentes del Depósito Legal. Dicha colección nacional se está viendo notablemente perjudicada por varios problemas, de los cuales el primero que es necesario resolver es el desfase de la legislación vigente sobre Depósito Legal, en la que ha de plasmarse el modelo de colección nacional por la que se quiere optar en España. En este sentido hay que señalar el hecho esperanzador de que el Departamento de Mantenimiento y Desarrollo de 
Colecciones de la Biblioteca Nacional tenga planteado, entre otros retos, contribuir a la elaboración de una Ley de Depósito Legal que se adecue a la situación bibliotecaria actual (20). Sin embargo, la elaboración de esta Ley se enfrenta con grandes dificultades, como demuestra el hecho de la gran demora en su aparición y depende del concurso de un amplio colectivo integrado, al menos, por investigadores, bibliotecarios, editores y políticos.

- Préstamo interbibliotecario. En el plano de la cooperación el préstamo interbibliotecario juega un papel muy importante. Como ya hemos señalado anteriormente, suprimida la Biblioteca Nacional de Préstamo, el servicio quedó incorporado a la Biblioteca Nacional, que como primer centro bibliotecario del país tiene la responsabilidad de su organización y desarrollo. Consciente de ello lleva a cabo una serie de proyectos para potenciar dichos servicios. De todos ellos el más importante es la creación del Centro Nacional de Acceso al Documento, situado en el edificio que la Biblioteca Nacional tiene en Alcalá de Henares, donde dispone de tres módulos de ocho plantas cada uno y de una superficie de $25.000 \mathrm{~m} 2$.

- Bibliografía Nacional Española. Aunque también se edita en papel, desde 1992 lo hace en CD-ROM y puntualmente. Esta última circunstancia hace que la Biblioteca Nacional cumpla con la responsabilidad que, como cabecera del Sistema Bibliotecario Español tiene adquirida con el resto de las bibliotecas españolas. Subsanado el problema de su retraso en la publicación con que se enfrentaba en épocas anteriores, actualmente se encuentra con el riesgo de duplicación que supone la existencia de distintas bibliografías regionales. Este problema hunde sus raíces en el hecho de que todavía no se ha definido con claridad el papel que la Biblioteca Nacional debe cumplir en el Sistema Bibliotecario Español (21).

\subsubsection{Las bibliotecas públicas de titularidad estatal}

La existencia de estas bibliotecas aparece recogida en el artículo 149.1 (28 $)$ de la Constitución española. Conforman una red de 51 bibliotecas, generalmente situadas en las capitales de provincia, algunas de las cuales nacieron para albergar los fondos procedentes de la desamortización de Mendizábal. Salvo excepciones, han sido receptoras del Depósito Legal desde su creación. En virtud de lo anterior algunas poseen un importante fondo antiguo y una interesante colección local.

La condición de ser de "titularidad estatal" se traduce en que el Estado es propietario de las instalaciones y el responsable de las inversiones que se lleven a cabo en las mismas. Es también quien establece el Reglamento general como ha hecho a través del Real Decreto 582/1989, de 19 de mayo. Por medio de los convenios de gestión, firmados entre el Ministerio de Cultura y las distintas comuni- 


\section{Luisa Orera Orera}

dades autónomas., estas bibliotecas han pasado a ser gestionadas por estas últimas (22). Esto se traduce en que las comunidades autónomas. son responsables de la prestación de servicios. Así mismo se encargan de la elaboración de los reglamentos de funcionamiento interno. Para llevar a cabo lo anterior se ha transferido a las comunidades autónomas. el personal y el presupuesto que el Estado gastaba en el mantenimiento de dichas bibliotecas. Los gastos de inversión nueva siguen figurando en los Presupuestos del Estado. En este último plano hay que citar el Plan de Inversiones en las Bibliotecas Públicas del Estado (INVERCAS), iniciado en 1983 con el objetivo de construir nuevos edificios o remodelar los existentes. También el Estado está llevando a cabo un Proyecto de Informatización de la Red de Bibliotecas Públicas del Estado (PROINRED), que comenzó en 1987 y que se encuentra en fase muy avanzada.

Consideradas globalmente, a pesar de los avances que en algunos aspectos se han producido en dichas bibliotecas, en la actualidad presentan algunas carencias. La colección ubicada en estas bibliotecas está por debajo de las recomendaciones de la IFLA, ya que supone un $21,30 \%$ respecto a la dotación óptima aconsejada, representando $0,43 \mathrm{vol} /$ habitante. Lo mismo ocurre con el personal que supone un 23,01\% también respecto a la dotación óptima aconsejada, representando un 0,23 por cada 2.500 habitantes. A ello hay que sumar la inadecuación de la plantilla: 250 bibliotecarios $(22,06 \%)$ frente a 873 personal administrativo, subalterno y auxiliar $(77,05 \%)$. Por otra parte se da una importante carencia de personal especializado en informática $(0,88 \%)$.(23)

En nuestra opinión, estas bibliotecas pueden actuar como un elemento importante dentro del Sistema Bibliotecario Español, ya que esta red de bibliotecas puede suponer:

- Un elemento de cohesión para el Sistema Bibliotecario Español, al depender la totalidad de las mismas, del Estado.

- Por otra parte, pueden ejercer dentro de los sistemas autonómicos como un elemento integrador de todas las bibliotecas públicas de la comunidad autónoma correspondiente, si ejercen como bibliotecas públicas provinciales, de las cuales podrían depender el resto de bibliotecas públicas de la comunidad.

- Finalmente al mantener la titularidad el Estado y la gestión las comunidades autónomas, estas bibliotecas pueden actuar como un nexo de unión entre el ámbito nacional y el ámbito autonómico. 


\subsubsection{Sistemas bibliotecarios autonómicos (24)}

El artículo $148.1\left(15^{\circ}\right)$ de la Constitución especifica que las comunidades autónomas podrán asumir competencias exclusivas en aquellas bibliotecas que no sean de titularidad estatal. Posteriormente, los estatutos de autonomía van a recoger estas competencias. Como ya hemos señalado, mediante los decretos de transferencias, las competencias que la Administración Central tenía en las bibliotecas públicas municipales, a través de los centros provinciales coordinadores de bibliotecas, pasan a las comunidades autónomas. No hay que olvidar, además, que el artículo 26 del la Ley Reguladora de las Bases del Régimen Local establece que los municipios de más de 5.000 habitantes tienen obligación de dar servicio de biblioteca. Por otra parte, las distintas comunidades autónomas gestionan las bibliotecas públicas de titularidad estatal, mediante los convenios de gestión.

Sobre la base legal constituida por los estatutos de autonomía, los decretos de transferencias y los convenios de gestión, además de la legislación específica de bibliotecas -que las distintas comunidades autónomas han desarrollado- se asientan los distintos sistemas bibliotecarios autonómicos.

En cuanto al modelo, dichos sistemas bibliotecarios, aunque con ciertas variantes, suelen ajustarse a un esquema de tipo general, integrado, salvo excepciones, sólo por bibliotecas públicas. Casi todas las leyes señalan que los correspondientes sistemas bibliotecarios están compuestos por órganos y centros. Los órganos suelen ser:

- La Consejería de Educación, Cultura, etc. que se encuentra en la cúspide. De ella depende el Servicio de Bibliotecas, órgano coordinador de la actuación bibliotecaria con un carácter administrativo y técnico. De dicha Consejería depende también un centro técnico, cabecera del sistema, que es la Biblioteca Central, Regional, etc.

- El Consejo de Bibliotecas, órgano con carácter consultivo y asesor y formado por una serie de vocales natos o por designación del Consejero de Cultura o equivalente, entre los cuales suele haber representantes de los diversos tipos de bibliotecas e instituciones bibliotecarias de la comunidad en cuestión.

En cuanto a los centros bibliotecarios, casi todas las leyes autonómicas plantean un esquema en el que aparecen las siguientes bibliotecas:

- La Biblioteca Central, que actúa como cabecera del sistema.

- La Red De Bibliotecas Públicas de Titularidad Estatal (sólo en cuanto a su gestión). 
- Las bibliotecas públicas municipales que dependen en general, del Servicio de Bibliotecas, a través de los centros provinciales coordinadores, salvo en la comunidades autónomas donde se han suprimido.

Los actuales sistemas bibliotecarios autonómicos, hablando siempre de forma general, se enfrentan a problemas heredados -que en algunos casos han empeorado- y a otros nuevos.(25) Entre los ya heredados hay que citar la secular falta de medios (insuficiencia de colecciones, de personal, etc.) y la falta de planificación a la hora de crear bibliotecas públicas municipales, ya que no siempre se han creado allí donde se necesitaban, sino donde los ayuntamientos las han solicitado. Entre los nuevos, hay que destacar la indefinición en los canales de comunicación entre las bibliotecas pertenecientes a los mismos, y por lo tanto la precariedad de dichos sistemas.

A la desconexión de los antiguos sistemas provinciales, hay que unir la actual desconexión resultante de la superposición sobre la estructura anterior -basada, como ya hemos señalado, en la existencia de un Centro Nacional de Lectura, las bibliotecas provinciales y los centros coordinadores- de otra nueva estructura que se basa esta vez en la existencia del Servicio de Bibliotecas, la Biblioteca Central, las bibliotecas públicas del estado y los centros coordinadores de bibliotecas, pero sin llevar a cabo los ajustes necesarios para intercomunicar todas las bibliotecas. El resultado es la falta de claridad en los nexos de unión entre las distintas bibliotecas que integran los distintos sistemas bibliotecarios autonómicos. De todas formas, en aquellas comunidades autónomas en las que se optó por un sistema centralizado con la supresión de los centros coordinadores como es el caso, entre otros, de Aragón, la situación lejos de mejorar, se ha agravado más si cabe (26)

\subsubsection{Las Bibliotecas Centrales de las Comunidades Autónomas (27)}

Tienen su origen en el nacimiento de los sistemas bibliotecarios autonómicos, dentro de los cuales, son concebidas como los centros bibliotecarios superiores.

De lo dicho se deduce que -excepto la Biblioteca de Cataluña, existente desde 1907- son de reciente creación, a través de las leyes y decretos que crean y desarrollan los recientes sistemas bibliotecarios autonómicos. También, y exceptuando de nuevo la Biblioteca de Cataluña, todas ellas se han ubicado en el mismo edificio que la correspondiente biblioteca pública del Estado. Esto ha tenido en principio algunas ventajas (28) como:

- Un ahorro económico inicial para las comunidades autónomas, al no tener que construir un edificio para albergar dichas bibliotecas. 
- Un ahorro en los gastos de mantenimiento de estas bibliotecas y las públicas, ya que no hay que olvidar que la gestión de las bibliotecas públicas del Estado corre también por cuenta de las comunidades autónomas.

- Comodidad para el usuario, que accede en el mismo edificio a los servicios de dos bibliotecas distintas.

- Posibilidad de centralizar o toda o una parte, al menos, de la colección de la comunidad autónoma, ya que las bibliotecas públicas del Estado suelen disponer de una parte de la colección retrospectiva por haber sido receptoras del Depósito Legal con anterioridad a la creación de las comunidades autónomas. La posibilidad de unificación de dichas colecciones varia naturalmente entre comunidades, siendo mayor en las uniprovinciales que en las comunidades integradas por más de una provincia, ya que en ellas está más dispersa al disponer de más de una biblioteca pública del Estado. De todas formas hay excepciones, pues en algunas provincias las bibliotecas receptoras del Depósito Legal han sido las universitarias.

No obstante, el aprovechamiento de los edificios de las bibliotecas públicas del Estado, también plantea dificultades:

- Por las características propias de cada una de ellas, el tipo de colección, las funciones y servicios y los usuarios de ambos tipos de bibliotecas son diferentes. Por tanto los edificios de las bibliotecas públicas no son adecuados para albergar las bibliotecas centrales.

- El crecimiento de estas bibliotecas ha generado importantes problemas de espacio que afectan a las bibliotecas regionales y a las bibliotecas públicas, lo que ha planteado ya el traslado de aquellas a edificios propios. Quizá este hecho, que supone la construcción o rehabilitación de un edificio y el traslado de los fondos, no solo anula el ahorro inicial que para las comunidades autónomas. supuso el aprovechamiento de los edificios de las bibliotecas públicas, sino que supondrá quizá a la larga un gasto añadido.

Las funciones asignadas a estas bibliotecas dentro de las comunidades autónomas. son similares a las ejercidas por la Biblioteca Nacional respecto al Estado español, con la diferencia obvia de que el marco en que se ejercen unas y otras es distinto, lo que libera a dichas bibliotecas de las responsabilidades que tanto en el plano nacional como internacional competen a la Biblioteca Nacional. Las principales funciones a que nos referíamos son las siguientes:

- Actuar, dentro de los sistemas bibliotecarios autonómicos como centro bibliotecario superior.

- Recopilar, conservar y difundir el patrimonio bibliográfico y documental producido dentro de la comunidad, e ingresado en las mismas a través del 
Depósito Legal. Asimismo, tiene también las mismas funciones respecto a todos aquellos documentos producidos fuera de la comunidad, pero que hagan referencia a la misma.

- Elaborar la bibliografía de la comunidad autónoma, así como el catálogo colectivo (mediante el correspondiente convenio con el Ministerio de Cultura).

Si ejercen realmente sus funciones, las bibliotecas centrales pueden llegar a ser un nexo de unión tanto para las distintas bibliotecas pertenecientes a la comunidad autónoma, como entre el sistema bibliotecario autonómico correspondiente y el Sistema Bibliotecario Español, a través de la Biblioteca Nacional.

Una vez que casi todas las comunidades autónomas. han optado por la creación de una biblioteca central, no nos planteamos ya si son o no necesarias estas bibliotecas. Sí queremos reflexionar sobre el hecho de que quizá el mayor peligro inherente a las mismas sea el riesgo de duplicación de colecciones y funciones respecto a otras bibliotecas, lo que las convertiría en centros antieconómicos y en cierta medida inútiles. Este riesgo de duplicación se da, por ejemplo, en la función de crear la colección bibliográfica de la comunidad. No hay que olvidar que estas bibliotecas son de reciente creación, y que por tanto, la colección retrospectiva se halla situada en aquella o aquellas bibliotecas que habían sido anteriormente receptoras del Depósito Legal, generalmente, como ya hemos señalado, se trata o de las bibliotecas públicas del Estado o de algunas bibliotecas universitarias. La ubicación de la colección retrospectiva en estas bibliotecas supondría o bien el traslado desde las bibliotecas donde estuviera ubicada, algo no aconsejable, o bien la duplicación de la misma. Por lo tanto en este campo la misión de las bibliotecas centrales es sobre todo, el estudio de dicha colección retrospectiva mediante la confección del catálogo colectivo del patrimonio bibliográfico de la comunidad.

Por otra parte, el riesgo de duplicación se da también respecto a la Biblioteca Nacional, entre la colección nacional -ubicada en la Biblioteca Nacional- y las colecciones regionales -ubicadas en las bibliotecas centrales-. Igualmente surge el mismo peligro en el campo de la bibliografía nacional corriente y las distintas bibliografías regionales, que algunas comunidades autónomas. ya realizan. La existencia de los sistemas bibliotecarios autonómicos, con las bibliotecas regionales a la cabeza, y las competencias de éstas en materia de Depósito Legal y todas las funciones relacionadas con el mismo impone, como ya hemos dicho anteriormente, la necesidad de un reajuste de la legislación sobre Depósito Legal, así como la coordinación entre el contenido de la bibliografía nacional y las distintas bibliografías regionales. 


\section{Notas}

(1) Norma ISO 5.127

(2) Sobre el desarrollo histórico de las bibliotecas públicas en España pueden consultarse los capítulos correspondientes de : Escolar, Hipólito. Historia de las bibliotecas. Madrid: Fundación Germán Sánchez Ruipérez, 1985

(3) Martinez Gonzalez, J. Sistemas de bibliotecas públicas en España y sus órganos de gestión. Una hipótesis histórica. Boletín de la Asociación Andaluza de Bibliotecarios. 12-13 (Diciembre 1988) p. 77.

(4) Se exceptuaron las dedicadas a la enseñanza de los niños pobres, y a la asistencia de ancianos. La excepción se amplió después a los conventos que educaban misioneros para Filipinas.

(5) Martinez Gonzalez, J. Sistemas de bibliotecas públicas..., op.cit., p. 79

(6) No obstante se conservan algunos resultados como las bibliotecas populares de Madrid, que como se ve siguen conservando el nombre de populares, sin que ello suponga ninguna diferencia frente al resto de bibliotecas públicas del territorio nacional. En esta línea hay que situar también al movimiento bibliotecario catalán de principios del siglo XX.

(7) Escolar, Hipólito. Historia de las bibliotecas..., op.cit., p. 475

(8) Martínez González, J. Sistemas de bibliotecas públicas... Op.cit., p. 84

(9) Méndez Aparicio, J. El Sistema informativo nacional español. Carencias de sus pilares básicos, las bibliotecas públicas // Boletín de la ANABAD. 44:2 (Abril/junio, 1994) $90 \mathrm{ss}$.

(10)Artículo 148.1. (15º)

(11)Artículo 149.1. (28 $)$

(12)Artículo 149.2.

(13)Real Decreto 1887/1996, de 2 de agosto, de estructura orgánica básica del Ministerio de Educación y Cultura (BOE nº 189, de 6 de agosto de 1996).

(14)Pueden consultarse los capítulos correspondientes de: Orera Orera, Luisa. Manual de Biblioteconomía. Madrid: Síntesis, 1996, donde se recogen algunas de estas normas.

(15)Artículo 7.1.

(16)Sobre la época anterior pueden consultarse algunas disposiciones legislativas tales como el Decreto orgánico de 8 de marzo de 1957 (BOE de 25 de marzo) y la Orden del Ministerio de Educación Nacional del 20 de diciembre de 1957, por la que se aprueba el Reglamento de la Biblioteca Nacional (BOE de 8 de febrero)

(17)Artículo 97 de la Ley 31/1990, de 27 de diciembre, de Presupuestos Generales del Estado para 1991 (BOE 28 de diciembre)

(18)Real Decreto 1816/1993, de 18 de octubre, por el que se establece la estructura orgánica básica del Departamento y de sus organismos autónomos.

(19)Sobre la organización interna de la Biblioteca Nacional puede el capítulo 20 de: Orera Orera, Luisa (ed). Op. Cit.

Scire. 2 : 2 (jul.-dic. 1996) 99-120 
(20)Garcia Melero, Luis Angel. El Departamento de Mantenimiento y Desarrollo de las Colecciones de la Biblioteca Nacional // Bolet'n de la ANABAD. 2 (1994) 208-209.

(21)Véase el apartado 2.2.4.1. de este trabajo, referido a las bibliotecas centrales de la comunidades autónomas

(22)Convenios de gestión de bibliotecas públicas de titularidad estatal suscritos entre el Ministerio de Cultura y las CC AA: Andalucía. Resolución de 14-2-84 (BOE nº 16 de 18-1-85); Aragón. Resolución de 9-7-86 (BOE nº 207 de 29-8-86); Baleares. Resolución de 14-12-84 (BOE nº 16 de 18-1-85); Canarias. Resolución de 14 -12-84 (BOE no 16 de 18-1-85); Extremadura. Resolución de 9-5-89 (BOE nº 140 de 13-689); Cantabria. Resolución de 14-12-84 (BOE n ${ }^{\circ} 16$ de 18-1-85); Castilla-La Mancha. resolución de 14-12-84 (BOE nº 17 de 19-1-85); Castilla-León. Resolución del 9-6-86 (BOE n 169 de 16-7-86); Cataluña. Resolución de 14-4-82 (BOE nº 100 de 27-4-82); Galicia. Resolución de 14-12-89 (BOE n 103 de 19-12-89); Madrid. Resolución de 9-5-89 (BOE no 140 de 13-6-89); Murcia. Resolución de 14-12-84 (BOE nº 17 de 191-85); Rioja, La. Resolución de 14-12-84 (BOE nº 17 de 19-1-85); Valencia. Resolución de 14-12-84 (BOE nº 17 de 19-1-85); Asturias. Resolución (BOE nº 96 de 22-4-86 y no 168 de 15-7-91). Véase Mogio Jarnés, E. Comentario sobre la legislación bibliotecaria del Estado. Signatura. 4 (Septiembre/Diciembre 1993) 22.

(23)Bibliotecas Publicas del Estado: Estudio estadístico año 1994. Madrid: Subdirección General de Coordinación Bibliotecaria, 1995.

(24)Fuentes Romero, J.J.. Sistemas Bibliotecarios en el Estado español: situación actual. En I Conferencia de Bibliotecarios y Documentalistas Españoles. [Madrid]: Ministerio de Cultura, Centro de Coordinación Bibliotecaria, 1993, p. 113.137.

(25)Méndez Aparicio, J. El sistema informativo... Op. cit., p. 81-109

(26)Orera Orera, L. Bases legales del Sistema Bibliotecario de Aragón. Revista General de Información y Documentación, 1993, vol. 3, nº 2, p. 117-129.

(27)Sobre información referida a las distintas bibliotecas regionales existentes en España puede consultarse el capítulo 20 de: Orera Orera, Luisa (ed). Manual... Op. Cit.

(28)Fuentes Romero, Juan José. Las Bibliotecas Centrales de las Comunidades Autónomas: Análisis de la situación y perspectivas de su desarrollo // Terceras Jornadas Españolas de Documentación Automatizada. DOCUMAT 90. Palma de Mallorca: Universitat de les Illes Balears, 1 (1990) 166-186.

\section{Bibliografía}

Archivos, Bibliotecas, Centros de Documentación y Museos en el Estado de las Autonomías (1997). // Actas del VI Congreso Nacional de ANABAD. Murcia : ANABAD-Murcia, 1997.

Bravo Pijoan, J. (1984) Del Estado centralizado al Estado autonómico. El planteamiento en materia de información y documentación. // Primeras Jornadas Españolas de Documentación Automatizada. Madrid : CSIC, 1984, p. 811-828.

Las Bibliotecas Públicas del Estado (1991). Madrid : Ministerio de Cultura, Centro de Coordinación Bibliotecaria, 1991. 
Directrices para un Plan Nacional de actuación 1983/86 en materia de Documentación e Información Científica y técnica (1983). Madrid : Ministerio de Educación y Ciencia, Secretaría de Estado de Universidades e Investigación, 1983.

Fonseca Ruiz, I. (1977) La lectura pública en España : pasado, presente y deseable futuro. // Boletín de la ANABAD. 27 : 2 (Abril/Junio 1977) 3-27.

Fuentes Romero, J.J. (1990) Las Bibliotecas Centrales de las Comunidades Autónomas: Análisis de la situación y perspectivas de su desarrollo. // Terceras Jornadas Españolas de Documentación Automatizada: DOCUMAT 90. Palma de Mallorca : Universitat de les Illes Balears, 1990, p. 166-186

Fuentes Romero, J.J. (1995). Sistemas Bibliotecarios en el Estado Español : Situación actual // I Conferencia de Bibliotecarios y Documentalistas Españoles. [Madrid] : Ministerio de Cultura, Centro de Coordinación Bibliotecaria, 1993, p. 113-137.

García Valenzuela, H.(1990). Nuevas aportaciones en materia de legislación sobre bibliotecas y personal bibliotecario. // Ciencias de la Documentación. 1 (1990) 103-113.

García Victoria, J. ; García Viñas,O. ; Ocaña Triguero, P. (1995). Aproximación a la legislación bibliotecaria de los países de la Unión Europea. // Boletín de la ANABAD. 45:4 (Octubre/Diciembre 1995) 57-144.

Girón García, A. (1985). Definición de funciones y planificación de servicios técnicos de bibliotecas en el ámbito estatal y en el ámbito autonómico. // Boletín de la ANABAD. 35 : 2-3 (Abril/Septiembre 1985) 263-269.

Girón García, A. (1984). La organización bibliotecaria española en el Estado de las Autonomías. // Análisis e Investigaciones Culturales. 14 (1984) 11-24.

Gómez Hernández, José A. (1993). Las preocupaciones por la lectura pública en España: Las bibliotecas "populares" : De las Cortes de Cádiz al plan de bibliotecas de María Moliner.// Revista General de Información y Documentación.. 3 : 2 (1993) 55-94.

Gonzalo, M.A., Macia, M. (1990). La legislación española de bibliotecas. // Boletín de la ANABAD. 40 : 2-3 (Abr.-Sept. 1990) 65-93.

Jerez Amador de los Ríos, M. J. (1988). Panorama actual de la situación bibliotecaria española // Boletín de la Asociación Andaluza de Bibliotecarios. 12-13 (Dic. 1988) $15-21$.

Jerez Amador de los Ríos, M.J. (1990) Sistema Bibliotecario Español y Red de Bibliotecas Públicas. // Ciencias de la Documentación. 1 (1990) 7-13.

Márquez Cruz, G. (1988). Marco normativo del Sistema Español de Bibliotecas. // Boletín de la Asociación andaluza de Bibliotecarios. 12-13 (Junio/Diciembre 1988) 131- 139.

Márquez Cruz, G. (1988) Sociología de la biblioteca pública en España en el proceso de modernización : de los orígenes de la organización bibliotecaria a la burocratización de la lectura (1808-1939). // Boletín de la Asociación Andaluza de Bibliotecarios. 1213 (Diciembre 198) 23-55.

Martínez González, J.(1981) Comunidades Autónomas y bibliotecas. // Boletín de la ANABAD. 31 : 4 (Oct-Dic. 1981) 591-597.

Martínez González, J.(1988) Sistemas de bibliotecas públicas en España y sus órganos de gestión: Una hipótesis histórica. // Boletín de la Asociación Andaluza de Bibliotecarios. 12-13 (Jun. 1988) 77-103.

Scire. 2 : 2 (jul.-dic. 1996) 99-120 


\section{0}

Méndez Aparicio, J.(1984). La biblioteca pública : ¿índice de subdesarrollo español?. Madrid : La autora, 1984.

Méndez Aparicio, J.(1994). El Sistema informativo nacional español. Carencias de sus pilares básicos, las bibliotecas públicas. // Boletín de la ANABAD. 34 : 2 (Abr.Jun.1994) 81-109.

Muñoz Choclán, J.(1987). Competencias administrativas en materia de lectura pública. // V Jornadas Bibliotecarias de Andalucía. Almería : Diputación Provincial, 1987. p. 2127.

Navarro Mallebrera, R., Torres Zapico, M. R.(1985). Las bibliotecas públicas municipales en la Ley Reguladora de las Bases del Régimen Local. // Boletín de la ANABAD. 35: 1 (Ene.-Mar. 1985) 98-101.

Oliver, V. (1978). Consideraciones en torno a una Ley de Bibliotecas Públicas. // Boletín de la ANABAD. $28: 4$ (Oct.-Dic. 1978) 15-18.

Oliver, V. (1980). El papel de las bibliotecas en los Sistemas Nacionales de Información Científica. // Boletín de la ANABAD. 30 : 1 (Ene.-Mar. 1980) 35-41.

Orera Orera, Luisa (ed) (1996). Manual de Biblioteconomía. Madrid : Síntesis, 1996.

Peón Pérez, J.L. (1992). El Estatuto de la Biblioteca Nacional como organismo autónomo. // Revista General de Información y Documentación. 2 : 2 (1992) 161-171.

Peón Pérez, J.L. (1991). El Reglamento de Bibliotecas Públicas del Estado y del Sistema español de Bibliotecas. // Documentación de las Ciencias de la Información. 1: 14 (1991) 87-94.

Recomendaciones para Centros Provinciales Coordinadores de Bibliotecas (1988). Madrid : Ministerio de Cultura, Centro de Coordinación Bibliotecaria, 1988.

Ros García, J. , López Yepes, J.(1994). Políticas de Información y Documentación. Madrid : Síntesis, 1994.

Textos legales. Bibliotecas (1983). Madrid : Ministerio de Cultura, Secretaría General Técnica, 1983. 